Document downloaded from:

http://hdl.handle.net/10251/49098

This paper must be cited as:

Bartovsky, P.; Domingo, LR.; Jornet Olivé, MD.; Miranda Alonso, MÁ.; Tormos Faus, RE. (2012). The triplet excited state of the biocative compound thiabendazole. Characterization and suitability as reporter for cyclodextrin complexation. Chemical Physics Letters. 525526:166-170. doi:10.1016/j.cplett.2012.01.001.

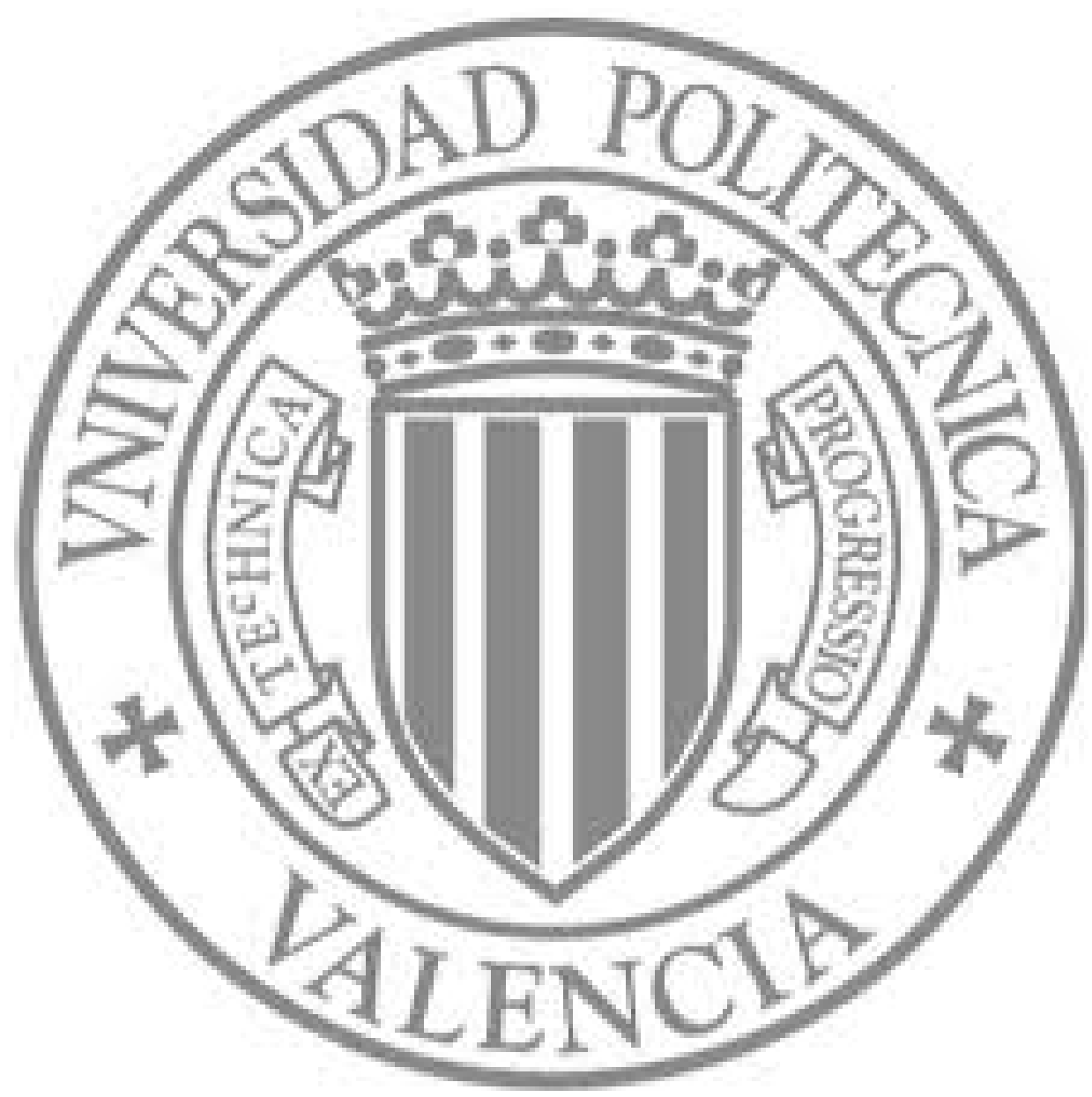

The final publication is available at

http://dx.doi.org/10.1016/j.cplett.2012.01.001

Copyright Elsevier 


\title{
The triplet excited state of the bioactive compound thiabendazole. Characterization and suitability as reporter for cyclodextrin complexation
}

\author{
Pavel Bartovsky, ${ }^{1}$ Luis R. Domingo, ${ }^{2}$ Dolors Jornet, ${ }^{1}$ Rosa Tormos ${ }^{1}$ and Miguel A. Miranda ${ }^{1}$ * \\ ${ }^{1}$ Departamento de Química/Instituto de Tecnología Química UPV-CSIC, Universidad Politécnica de \\ Valencia, Avenida de los Naranjos s/n, E-46022 Valencia, Spain and ${ }^{2}$ Departamento de Química \\ Orgánica, Universidad de Valencia, Dr. Moliner 50, E 46100 Burjassot, Valencia, Spain. \\ mmiranda@qim.upv.es
}

RECEIVED DATE (to be automatically inserted after your manuscript is accepted if required according to the journal that you are submitting your paper to)

Corresponding author. Address: Instituto de Tecnología Química UPV-CSIC, Universidad Politécnica de Valencia, Avenida de los Naranjos s/n, E-46022 Valencia, Spain. Fax: +34 963877809. E-mail address: mmiranda@qim.upv.es (M. A. Miranda)

Fluorescence spectroscopy, laser flash photolysis (LPF), and density functional theory calculations have been performed to characterize the photobehavior of thiabendazole (1). Direct LFP of $\mathbf{1}$ results in the generation of a transient absorbing at $\lambda_{\max }=570 \mathrm{~nm}$ identified as the triplet excited state $\left({ }^{3} 1^{*}\right)$. The intersystem crossing quantum yield is 0.91 , and the triplet energy is $288 \mathrm{~kJ} \mathrm{~mol}^{-1}$. The singlet-triplet energy gap is $84 \mathrm{~kJ} \mathrm{~mol}^{-1}$.

The behavior of thiabendazole within CDs results in a marked enhanced of the triplet lifetime, this change is attributed to the mobility restrictions of included $\mathbf{1}$ imposed by the cyclodextrin cavities.

\section{Introduction}

Benzimidazoles (BZs) are a family of heterocyclic compounds with a broad spectrum of anthelmintic activity and are effective as anti-nematode and anti-protozoal agents. ${ }^{1}$ In addition, many of them are used extensively on fruits and vegetables as post-harvest fungicides. ${ }^{2}$ Frequently, the biological action of benzimidazoles is limited by their low solubility in water. Different strategies have been developed for enhancing the solubility of these biocides. In this context, formation of cyclodextrin inclusion complexes is frequently used by pharmaceutical industry to increase the bioavailability of poorly soluble drugs. ${ }^{3}$ As a result of complex formation the physicochemical properties of the guest molecule, such as solubility or stability, may change significantly.

In the last years, a number of members of the BZ family have attracted considerable attention due to their anti-tumoral behavior. ${ }^{4}$ Thus, in the course of investigations on the development of anthelmintic 
resistance to BZs it has been discovered that they act binding specifically and with high affinity of the $\beta$ TUB monomer. ${ }^{5}$

Specifically, thiabendazole (1) is a bioactive benzimidazole used as human and veterinary anthelmintic. ${ }^{6}$ Together with its major metabolite, 5-hydroxythiabendazole, it has been monitored to trace drug residues by means of a fluorometric methodology. ${ }^{7,8}$ By contrast with the extensive use of $\mathbf{1}$, the photobehavior of this compound remains relatively unknown. In fact, the studies on the photochemistry of $\mathbf{1}$ are limited to aqueous or methanolic solutions and to the effect of singlet oxygen. ${ }^{9}$ Thus, it has been shown that the thiazole ring is the most labile moiety of the molecule; it undergoes ring cleavage, affording benzimidazole and benzimidazole-2-carboxamide. On the other hand, the singlet excited state of $\mathbf{1}$ has been characterized, and the phosphorescence in solid matrix has also been described. ${ }^{10}$ However, the triplet excited state or other possible transients generated by photolysis of $\mathbf{1}$ in solution have not been investigated as yet. With this background, the aim of the present work is the full characterization of photophysical properties of thiabendazole triplet. This knowledge is an essential requirement to explore, in a later stage, the possibility of using the triplet excited state of $\mathbf{1}$ as a probe for host-guest interactions, such as complexation with cyclodextrin or, more interestingly, interactions with tubulin. This is connected with the recent finding that drug triplet excited states can be used as reporters for protein binding sites, as their lifetimes are markedly sensitive to the microenvironment experienced within these biomacromolecules. ${ }^{11,12,13,14}$

\section{Results and Discusion}

In a preliminary stage, the absorption spectrum of $\mathbf{1}$ in acetonitrile was recorded. It presents a band centered at $300 \mathrm{~nm}\left(\varepsilon=15000 \mathrm{M}^{-1} \mathrm{~cm}^{-1}\right)$ with a shoulder at $310 \mathrm{~nm}$. In aqueous solutions the shape and position of the bands are very similar to those obtained in organic solvent.

The emission spectrum of $\mathbf{1}$ in acetonitrile when excited at $281 \mathrm{~nm}$ accompanied by the excitation band for the emission at $350 \mathrm{~nm}$, which is similar to the long-wavelength absorption band. The spectra registered in $\mathrm{PBS} / \mathrm{MeCN}$ matched with those obtained in acetonitrile. From the intersection between the excitation and emission after normalization, a singlet energy of $372 \mathrm{~kJ} \mathrm{~mol}^{-1}$ was determined. The emission quantum yield in deaereated MeCN solution was 0.06 and in PBS/MeCN (3/1, v/v) it was found to be 0.07 . These values are somewhat higher than those previously reported in $\mathrm{MeOH} .{ }^{10} \mathrm{The}$ fluorescence properties were insensitive to oxygen.

The phosphorescence spectrum of $\mathbf{1}$ in methanol at $77 \mathrm{~K}$ consisted of an almost structure less emission with a maximum at $475 \mathrm{~nm}$. The triplet energy was determined as $282 \mathrm{~kJ} \mathrm{~mol}^{-1}$.

\subsection{Transient absorption spectroscopy}

After examining the absorption and emission behavior, transient absorption spectroscopy studies were undertaken. Thus, $266 \mathrm{~nm}$ laser flash photolysis (LPF) of 1 in deaerated acetonitrile or PBS/MeCN (3/1, v/v) solutions led to transients absorbing in the 350-700 $\mathrm{nm}$ range. The spectra obtained after the laser pulse showed a broad band centered at $570 \mathrm{~nm}$, which was ascribed to the T-T absorption (Figure 1). The 
lifetime was found to be $1.0 \mu$ s in acetonitrile and $3.4 \mu$ s in PBS and was dependent on the concentration of $\mathbf{1}$, with a self-quenching rate constant in the order of $10^{9} \mathrm{M}^{-1} \mathrm{~s}^{-1}$.

As expected for a triplet, it was sensitive to the presence of oxygen. From the Stern-Volmer plot (Figure 1, inset), a $\mathrm{k}_{\mathrm{q}}$ value of $6.6 \times 10^{9} \mathrm{M}^{-1} \mathrm{~s}^{-1}$ was determined for $\mathbf{1}$ in acetonitrile.

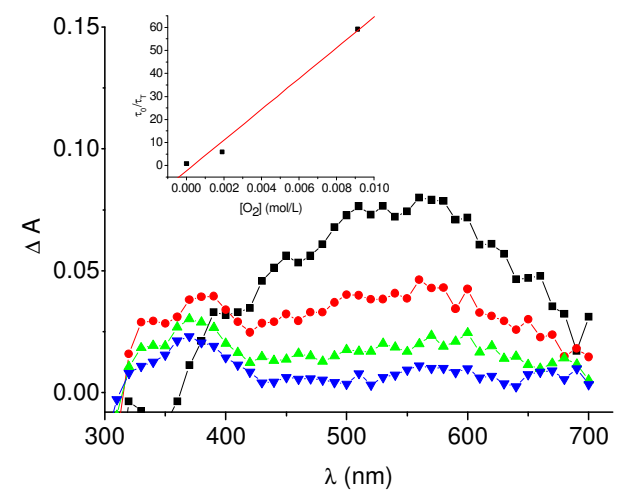

Fig. 1. Transient absorption spectra of thiabendazole $\left(4.0 \times 10^{-3} \mathrm{M}\right)$ in $\mathrm{MeCN}$ after $266 \mathrm{~nm}$ irradiation, registered at $0.23 \mu \mathrm{s}(\mathbf{(})$, $1.0 \mu \mathrm{s}(\bullet), 2.17 \mu \mathrm{s}(\Delta)$ and $4.52 \mu \mathrm{s}(\mathbf{\nabla})$ delay times. Inset: Stern-Volmer plot obtained for triplet quenching by $\mathrm{O}_{2}$ in $\mathrm{MeCN}$.

Moreover, alternative generation of the triplet by sensitization with xanthone $\left(\mathrm{E}_{\mathrm{T}}=310 \mathrm{~kJ} \mathrm{~mol}^{-1}\right)^{15}$ and 4,4'-dimethoxybenzophenone $\left(\mathrm{E}_{\mathrm{T}}=282 \mathrm{~kJ} \mathrm{~mol}^{-1}\right)^{16}$ was used for characterizing the transient. Thus, LFP of a deaereated xanthone solution in $\mathrm{PBS} / \mathrm{MeCN}$ at $355 \mathrm{~nm}$ produced xanthone triplet with maximum at ca. $600 \mathrm{~nm}$. In the presence of thiabendazole, transformation of this sharp band into a broader signal with maximum at $575 \mathrm{~nm}$ was observed (not shown). Figure 1 shows the growth and decay of the triplet thiabendazole signal at $500 \mathrm{~nm}$, upon addition of increasing amounts of 1 to xanthone (from 0:1 to 20:1 molar ratio). From the corresponding decays at $600 \mathrm{~nm}$, the rate constant of this energy transfer process was found to be $1.5 \times 10^{9} \mathrm{M}^{-1} \mathrm{~s}^{-1}$.

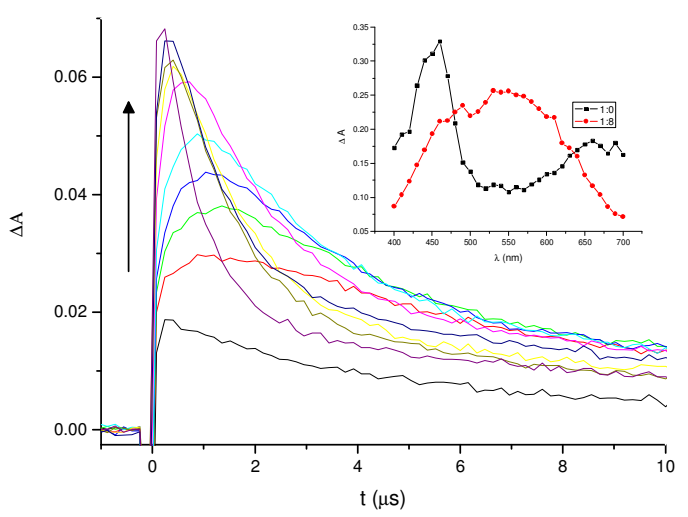

Fig. 2. Sensitization of thiabendazole triplet via energy transfer from xanthone triplet excited state in deaerated PBS/MeCN (3:1.v/v), registration wavelength: $\lambda_{\text {reg }}=500 \mathrm{~nm}$. The 1 : xanthone ratios were changed from 0:1 to $20: 1$ Inset: Sensitization of 1 triplet via T-T energy transfer from DMBP. Excitation wavelength: $\lambda=355 \mathrm{~nm}$, solvent: PBS/MeCN (3:1). Spectra of DMBP alone $(\mathbf{a})$ and in the presence of $\mathbf{1}(\bullet)$ recorded $0.4 \mu$ s after the laser pulse 
Likewise, when the sensitizer was 4,4'-dimethoxybenzophenone (DMBP) deactivation of the aromatic ketone triplet occurred with the concomitant appearance of the $\mathbf{1}$ triplet. This is clearly shown in Figure 2 (inset).

In this case, the rate constant for energy transfer was $3.9 \times 10^{8} \mathrm{M}^{-1} \mathrm{~s}^{-1}$, one order of magnitude lower than that obtained for xanthone, indicating that the triplet energies of $\mathbf{1}$ and DMBP must be close to each other.

In addition, different triplet acceptors trans-stilbene, acenaphthene and naphthalene were used to quench the T-T absorption band of $\mathbf{1}$; the rate constants for the involved processes were $1.0 \times 10^{9} \mathrm{M}^{-1} \mathrm{~s}^{-1}, 9.8 \times 10^{9}$ $\mathrm{M}^{-1} \mathrm{~s}^{-1}$ and $5.5 \times 10^{9} \mathrm{M}^{-1} \mathrm{~s}^{-1}$, respectively

Overall, the above data indicate that the triplet energy of thiabendazole must be close to $282 \mathrm{~kJ} \mathrm{~mol}^{-1}$. In order to obtain a narrower range for this parameter, quenching of the T-T absorption of DMBP in PBS:acetonitrile was investigated by LFP at $355 \mathrm{~nm}$, in the presence of increasing amounts of several acceptors $^{15}$ including 1 . The decay of the $430 \mathrm{~nm}$ band was analyzed, to determine the quenching rate constants. When the reciprocal DMBP triplet lifetimes were plotted against the quencher concentrations, different straight lines were obtained (not shown); their slopes (intermolecular $\mathrm{k}_{\mathrm{ET}}$ values) are given in Table 1.

Table 1.

\begin{tabular}{|c|c|c|}
\hline & $\begin{array}{l}\mathbf{E}_{\mathrm{T}} \\
\mathrm{kJ} \mathrm{mol}^{-1}\end{array}$ & $\begin{array}{l}\mathbf{k}_{\mathbf{E T}}\left(\mathbf{M}^{-1} \mathbf{s}^{-1}\right) \\
\text { PBS:MeCN }\end{array}$ \\
\hline 1,3-cyclohexadiene & 219 & $4.02 \times 10^{9}$ \\
\hline biphenyl & 271 & $4.90 \times 10^{9}$ \\
\hline fluorene & 282 & $4.60 \times 10^{9}$ \\
\hline dibenzofuran & 289 & $2.80 \times 10^{8}$ \\
\hline thiabendazole & $\mathrm{E}_{\mathrm{T}}(\mathbf{1})$ & $3.90 \times 10^{8}$ \\
\hline
\end{tabular}

The rate constant of triplet-triplet energy transfer $\left(\mathrm{k}_{\mathrm{ET}}\right)$ depends on the triplet energy gap $\left(\Delta \mathrm{E}_{\mathrm{T}}\right)$, between the donor and the acceptor, as given by Sandros' equation ${ }^{17}$ (1)

$$
\mathrm{k}_{\mathrm{ET}}=\left(\mathrm{k}_{\max } \mathrm{x} \mathrm{e}^{-\Delta \mathrm{ET} / \mathrm{RT}}\right) /\left(\mathrm{e}^{-\Delta \mathrm{ET} / \mathrm{RT}}+1\right)
$$

where $\mathrm{k}_{\max }$ is the optimum rate constant for the system. Thus, assuming a value of $\mathrm{k}_{\max }=4.5 \times 10^{9} \mathrm{M}^{-1} \mathrm{~s}^{-1}$, chosen as the average of the first three entries, $\Delta \mathrm{E}_{\mathrm{T}}$ resulted to be $6 \mathrm{~kJ} \mathrm{~mol}^{-1}$. Therefore, the triplet energy value of $\mathbf{1}$ is $\mathrm{E}_{\mathrm{T}}\left({ }_{1}\right) 288 \mathrm{~kJ} \mathrm{~mol}^{-1}$.

Furthermore, the molar absorption coefficient of thiabendazole triplet was determined using DMBP as standard $\left(\varepsilon=2700 \mathrm{~mol} \mathrm{~L}^{-1} \mathrm{~cm}^{-1}\right.$ at $\left.450 \mathrm{~nm}\right)$. In PBS/MeCN (3/1, v/v); it was found to be $3960 \mathrm{~mol} \mathrm{~L}^{-1} \mathrm{~cm}^{-1}$. The intersystem crossing (ISC) quantum yield $\left(\Phi_{\mathrm{ISC}}\right)$ of $\mathbf{1}$ in $\mathrm{PBS} / \mathrm{MeCN}$ was calculated from the $\Delta \mathrm{OD}$ of the T-T bands for isoabsorptive solutions of $\mathbf{1}$ and DMBP, taking into account the molar absorption coefficients of the two triplets and the known ISC quantum yield of DMBP (0.97). Its value was established at ca. 0.91.

\subsection{Theoretical DFT calculations}

Geometry optimization. The ground state geometry of $\mathbf{1}$ was first analyzed. Due to the free bond rotation around the C1-C6 single bond (see numbering scheme in Figure 3), two rotamers (1-c and 1-t) are feasible, where the NH group of benzimidazole and the $\mathrm{N}$ atom of thiazole present a $s$-cis or a $s$-trans arrangement. Hence, a conformational analysis was performed in order to characterize the most favorable structure. 


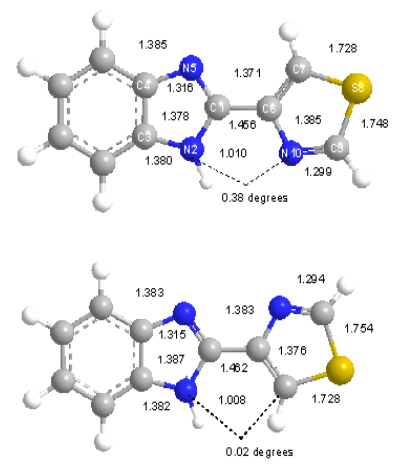

Fig. 3. B3LYP/6-31G(d) 1-c (top) and 1-t (bottom) structures. The lengths are given in Angstroms.

According to B3LYP/6-31G(d) optimization, 1-t is $31.7 \mathrm{~kJ} \mathrm{~mol}^{-1}$ higher in energy than 1-c. The interconversion between both conformers occurs via structure 1-90, in which the two heterocyclic systems are twisted 90 degrees, with an activation energy of $47 \mathrm{~kJ} \mathrm{~mol}^{-1}$. Although this cannot be considered a high barrier, based on the energy difference between 1-c and 1-t only the former will be considered in the singlet excitation study. Similar relative energies were obtained by full optimization at the B3LYP/6-311+G(d,p) level (see Table 2). A comparison between the B3LYP/6-31G(d) and B3LYP/6-311+G(d,p) geometries did not reveal significant differences, either.

Table 2

Total (E in a.u.) and Relative Energies $\left(\Delta \mathrm{E}\right.$ in $\left.\mathrm{kJ} \mathrm{mol}^{-1}\right)$ of the 1-c, 1-90 and 1-t Structures

\begin{tabular}{ccccc}
\hline & \multicolumn{2}{c}{ B3LYP/6-31G(d) } & \multicolumn{2}{c}{ B3LYP/6-311+G(d,p) } \\
\hline & $\mathrm{E}$ & $\Delta \mathrm{E}$ & $\mathrm{E}$ & $\Delta \mathrm{E}$ \\
\hline $\mathbf{1 - c}$ & -947.7350696 & & -947.902007 & \\
$\mathbf{1 - 9 0}$ & -947.7194715 & 41 & -947.887831 & 37 \\
$\mathbf{1 - t}$ & -947.7230448 & 32 & -947.889882 & 32 \\
\hline
\end{tabular}

Some geometrical parameters, together with the Wiberg bond order (BO) deserve special comments; they include: i) the C1-C6 bond length, $1.456 \AA$, and the corresponding BO value, 1.06, which point to a $\mathrm{Csp}^{2}-\mathrm{Csp}^{2}$ single bond, ii) the two S-C bond lengths, 1.728 and $1.748 \mathrm{~A}$, and the $\mathrm{BO}$ value, 1.21, characteristic of S-C single bonds with a slight $\pi$ character; iii) the C6-C7 and the C9-N10 bond lengths, 1.371 and 1.299 Ả, and the BO value, 1.56 and 1.65, suggesting a marked $\pi$ character, and iv) the N2-C1C6-N10 dihedral angle, 0.38 degrees, which accounts for the planar arrangement. The C1-C6 BO value indicates lack of conjugation between both ring systems in clear agreement with the low energy barrier associated with rotation around the C1-C6 bond.

Singlet and triplet excitation. The first three singlet and triplet excited states of 1-c were studied at the time-dependent (TD) B3LYP/6-311+G(d,p) level using the B3LYP/6-311+G(d,p) geometry. The excitation energies and oscillator strengths are given in Table 3.

Table 3.

TD B3LYP/6-311+G(d,p) Excitation Energies (EE in nm), Oscillator Strengths (f) and Relative Energies ${ }^{\mathrm{a}, \mathrm{b}}\left(\Delta \mathrm{E}\right.$ in $\left.\mathrm{kJ}^{\mathrm{mol}}{ }^{-1}\right)$ of the First Three Singlet and Triplet Excited States of 1-c.

\begin{tabular}{clclc}
\hline Excited State & Transition & EE & f & $\Delta \mathrm{E}$ \\
\hline S1 & $52 \pi \rightarrow 53 \pi^{*}(0.6490)$ & 307.1 & 2462 & $389(398)$
\end{tabular}




\begin{tabular}{lllll} 
S2 & $51 \pi \rightarrow 53 \pi^{*}(0.6760)$ & 291.7 & 0573 & $410(423)$ \\
S3 & $52 \pi \rightarrow 54 \pi^{*}(0.6399)$ & 270.1 & 3354 & $443(450)$ \\
T1 & $52 \pi \rightarrow 53 \pi^{*}(0.7026)$ & 434.8 & 0000 & $275(284)$ \\
T2 & $51 \pi \rightarrow 53 \pi^{*}(0.5016)$ & 364.6 & 0000 & $328(333)$ \\
T3 & $52 \pi \rightarrow 54 \pi^{*}(0.5360)$ & 326.4 & 0000 & $366(372)$ \\
\hline
\end{tabular}

In order to characterize the main molecular orbital (MO) contributors to these singlet and triplet excitations, B3LYP/6-31G(d) MOs 51 to 54 were analyzed. While MOs 51 and 52 correspond to HOMO1 and HOMO, MOs 53 and 54 correspond to LUMO and LUMO+1, respectively. The four MOs show a $\pi$ symmetry.

The first S1 singlet excited state presents an excitation energy of $307.1 \mathrm{~nm}(\mathrm{f}=0.2462)$ and corresponds mainly to a $\pi \rightarrow \pi^{*}$ excitation between HOMO and LUMO. It is located $389 \mathrm{~kJ} \mathrm{~mol}^{-1}$ above the S0 ground state.

The S2 singlet excited state presents an excitation energy of $291.7 \mathrm{~nm}(\mathrm{f}=0.0573)$, corresponding to a

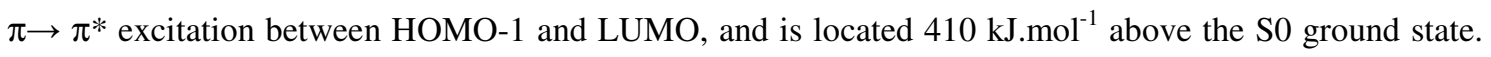
Finally, the S3 singlet excited state presents an excitation energy of $270.1 \mathrm{~nm}(\mathrm{f}=0.3354)$ and is basically associated with a $\pi \rightarrow \pi^{*}$ excitation between HOMO-1 and LUMO+1. It is located $443 \mathrm{~kJ} \mathrm{~mol}^{-1}$ above the S0 ground state.

The first T1 triplet state, generated by a $\pi \rightarrow \pi^{*}$ excitation between HOMO and LUMO presents an excitation energy of $434.8 \mathrm{~nm}$ and is located $275 \mathrm{~kJ} \mathrm{~mol}^{-1}$ above the S0 ground state. The T2 triplet excited state (excitation energy of $364.6 \mathrm{~nm}$ ) is associated with a $\pi \rightarrow \pi^{*}$ excitation between HOMO-1 and LUMO and is located $328 \mathrm{~kJ} \mathrm{~mol}^{-1}$ above the S0 ground state. The T3 triplet excited state, with excitation energy of $326.4 \mathrm{~nm}$, results from a $\pi \rightarrow \pi^{*}$ excitation between HOMO-1 and LUMO+1 and is located $366 \mathrm{~kJ} \mathrm{~mol}^{-1}$ above the S0 ground state. ocated $389 \mathrm{~kJ} \mathrm{~mol}^{-1}$.

Finally, the solvent effects (acetonitrile) on the energies of these singlet and triplet excited states were studied using the polarizable continuum model (PCM) by TD B3LYP(PCM)/6-311+G(d,p) calculations over the gas phase geometries. The relative energies are given in Table 4. For the singlet states the relative energies are $398(\mathrm{~S} 1), 423(\mathrm{~S} 2)$ and $450(\mathrm{~S} 3) \mathrm{kJ} \mathrm{mol}^{-1}$, while the triplet states are $284(\mathrm{~T} 1), 333$ (T2) and $372(\mathrm{~T}) \mathrm{kJ} \mathrm{mol}^{-1}$. Therefore, inclusion of solvent effects through a continuum model increases slightly the gas phase energies between $4-9 \mathrm{~kJ} \mathrm{~mol}^{-1}$

\subsection{Formation of cyclodextrin inclusion complexes}

In order to study the influence of microheterogeneous media on the behavior of the triplet excited state, 1 was included within $\alpha, \beta$ and $\gamma$ cyclodextrins (CDs). The formation stoidiametry and topology of complexes has been previously investigated by means of different techniques, such as ${ }^{1} \mathrm{HNMR}$, IR, fluorescence, solubility and absorption spectrophotometry. Thus, formation of the 1:1 complexes with moderate association constants has been determined for the three types of CDs. ${ }^{3}$ 
When solutions of $1\left(4 \times 10^{-5} \mathrm{M}\right)$ and CD in neutral buffer (0.05 M PBS) were submitted to LFP the transient absorption spectra obtained after laser excitation $\left(\lambda_{\text {exc }}=266 \mathrm{~nm}\right.$ ) were similar (Figure 4, upper inset) to that obtained for $\mathbf{1}$ in acetonitrile, although the signal intensity was higher than in the bulk solution. Figure $4 \mathrm{~A}$ shows a clear increase of the triplet absorption signal with the $[\beta-\mathrm{CD}] / \mathbf{1}$ molar ratio; however, for solubility limitations it was not possible to reach a plateau. The association constant $\left(\mathrm{K}_{\mathrm{A}}\right)$ value was determined from the relationship between the changes observed in the absorption $(\Delta \mathrm{A})$ at 570 $\mathrm{nm}$ as a function of the total cyclodextrin concentration $[C D]_{\mathrm{T}}$, (Figure 4 ). It can be related to the equilibrium complex formation according to Benesi-Hildebrand (eq 1) expression ${ }^{18}$ where $\Delta \varepsilon$ is the difference between the molar absorption coefficients for complexed and free thiabendazole.

$$
1 / \Delta \mathrm{A}=1 / \Delta \varepsilon[\mathbf{1}]_{\mathrm{T}}+1 / \mathrm{K}_{\mathrm{A}} \Delta \varepsilon[\mathbf{1}]_{\mathrm{T}}[\mathrm{CD}]_{\mathrm{T}}(1)
$$

From the values of intercept and slope of the straight lines fitted to the experimental data the association constant was estimated as $135 \mathrm{M}^{-1}$, which is in reasonable agreement with the values obtained for the same system by means of fluorescence or solubility measurements (ca. $100 \mathrm{M}^{-1}$ ). ${ }^{3}$ To our knowledge this is the first example where laser flash photolysis has been used to obtain the association constant for a CD complex.

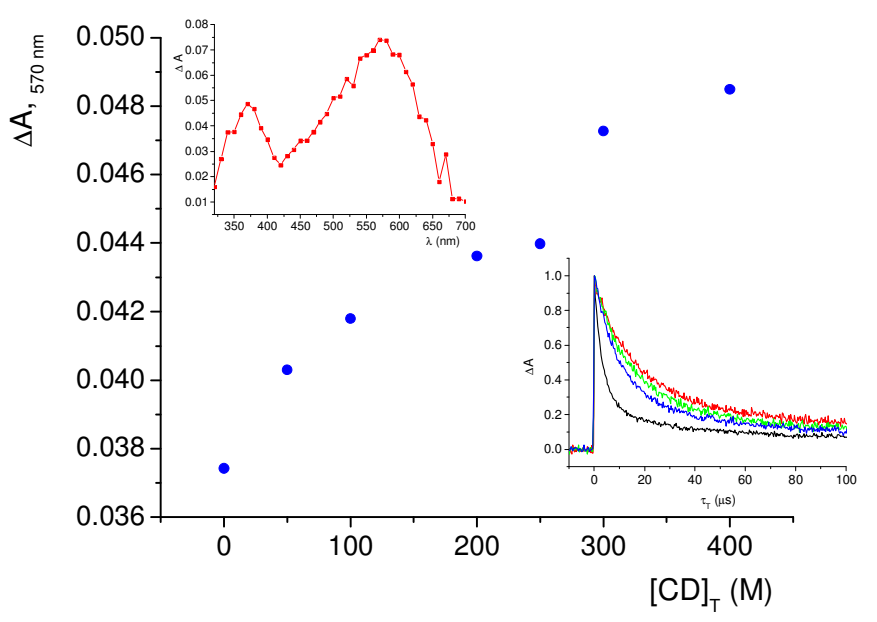

Fig. 4. Dependence of thiabendazole transient absorption signal at $\lambda_{\max }=570 \mathrm{~nm}$ versus $\beta-\mathrm{CD}$ molar concentration in aqueous solutions, at $25{ }^{\circ} \mathrm{C}$. Upper inset: transient absorption spectrum obtained by $266 \mathrm{~nm}$ laser flash photolysis of $1\left(4 \times 10^{-5} \mathrm{M}\right)$ in the presence of $\beta$-CD (1:440) registered $0.31 \mu$ s after the pulse. Lower inset: Normalized decays monitored at $570 \mathrm{~nm}$ for $1\left(4 \times 10^{-5} \mathrm{M}\right)$ in PBS, and in the presence of $\alpha$-CD $(1: 400) \bullet, \beta-C D(1: 440) \bullet$ and $\gamma$-CD (1:600) $\bullet$

The decays monitored at $570 \mathrm{~nm}$ in air equilibrated solutions, in the absence of CDs, fitted well with a first order kinetics. Conversely, in the presence of CDs two lifetimes, corresponding to the free and complexed forms, were necessary to fit the decays. As shown in Figure 4 lower inset, in the microheterogeneous system decays were markedly longer than in solution $(3.4 \mu \mathrm{s}, 12.2 \mu \mathrm{s}, 14.2 \mu \mathrm{s}, 9.5 \mu \mathrm{s}$ bulk solution, $\alpha, \beta$ and $\gamma \mathrm{CD}$, respectively).

This observation can be attributed to a slow-down of non radiative decay processes associated with the limited degrees of freedom. 
The longest lifetime was displayed by the $1 @ \beta-\mathrm{CD}$ complex, and the shortest by $1 @ \gamma-\mathrm{CD}$ complex. This must be related to the relative size of the CD cavities, which determines the degree of interaction. Interestingly, the triplet behavior was parallel to that shown by the singlet excited state in the same microenviroment. In fact when the fluorescence or triplet absorption signals $\mathrm{I} / \mathrm{I}_{0}$ (at 350 and 570 , respectively) were plotted versus the $[\beta-\mathrm{CD}] /[1]$ ratio, nearly superimposable trends were observed (Figure 5). Thus, a clear correlation exists between the singlet and triplet properties, as regards complexation with CD.

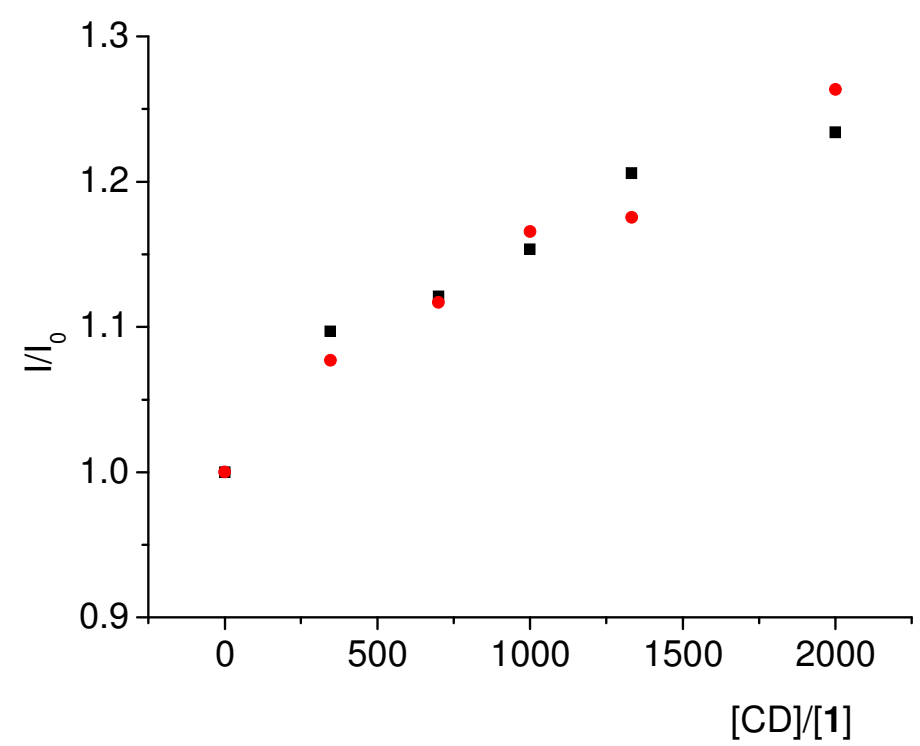

Fig. 5. Dependence of $\mathrm{I} / \mathrm{I}_{0}$ on $\beta-\mathrm{CD} / \mathbf{1}$ ratio by laser flash photolysis $(\bullet)$ and fluorescence measurements $(\boldsymbol{\bullet})$

\section{Conclusions}

Laser flash photolysis of thiabendazole at $266 \mathrm{~nm}$ gives rise to its $\pi \pi^{*}$ triplet excited state, detected as a broad transient absorption with maximum at $570 \mathrm{~nm}$. The intersystem quantum yield is very high $(0.91)$ and the triplet energy is $288 \mathrm{~kJ} \mathrm{~mol}^{-1}$.

The triplet lifetime is markedly medium dependent, increasing from $3.4 \mu$ s in aqueous solution to $14.2 \mu \mathrm{s}$ within the $\beta-\mathrm{CD}$ cavities. The intensity of the T-T signal also increases upon $\mathrm{CD}$ complexation; this change has been used to determine the binding constant, which has been estimated as $134 \mathrm{M}^{-1}$ for $\beta$-CD. This result is in good agreement with the value obtained by means of fluorescence measuraments.

\section{Experimental section}

\subsection{Materials and Solvents}

Thiabendazole (1), xanthone, 4,4'-dimethoxybenzophenone, 1,3-cyclohexadiene, trans-stilbene, acenaphthene, naphthalene, biphenyl, fluorene and dibenzofuran were purchased from Aldrich. Their purity was checked by ${ }^{1} \mathrm{H}-\mathrm{NMR}$ spectroscopy and high performance liquid chromatography (HPLC) analysis. Reagent grade solvent acetonitrile was purchased from Scharlau and used without further purification.

\subsection{Absorption Spectra}


Optical spectra in different solvents were measured on a Perkin Elmer Lambda 35 UV/Vis spectrophotometer. Emission spectra were recorded on a spectrofluorometer system, which was provided with an M 300 emission monochromator in the wavelength range of 200-900 $\mathrm{nm}$ and are uncorrected. Samples were placed into $10 \times 10 \mathrm{~mm}^{2}$ Suprasil quartz cells with a septum cap. Solutions were purged with nitrogen or oxygen for at least $10 \mathrm{~min}$ before the measurements. Fluorescence quantum yields were determined using $S$-flurbiprofen [ $S$-2-fluoro- $\alpha$-methyl-4-biphenylacetic acid] as reference $\left(\Phi_{\mathrm{F}}=0.27\right.$ at $\lambda_{\text {exc }}=281 \mathrm{~nm}$ in methanol as solvent).(17) The absorbance of the samples at the excitation wavelength was kept below 0.1. Excitation and emission slits were maintained unchanged during the emission experiments. For time-resolved fluorescence decay measurements, the conventional single photon counting was used. All experiments were performed at room temperature $\left(22^{\circ} \mathrm{C}\right)$.

\subsection{Laser Flash Photolysis (LFP)}

The LFP experiments were carried out by using a Q-switched Nd:YAG laser (Quantel Brilliant, 266 or $355 \mathrm{~nm}, 10$ or $14 \mathrm{~mJ}$ per pulse, $5 \mathrm{~ns}$ fwhm) coupled to a mLFP-111 Luzchem miniaturized equipment. This transient absorption spectrometer includes a ceramic xenon light source, $125 \mathrm{~mm}$ monochromator, Tektronix 9-bit digitizer TDS-3000 series with $300 \mathrm{MHz}$ bandwith, compact photomultiplier and power supply, cell holder and fiber optic connectors, fiber optic sensor for laser-sensing pretrigger signal, computer interfaces and a software package developed in the LabVIEW environment from National Instruments. The LFP equipment supplies $5 \mathrm{~V}$ trigger pulses with programmable frequency and delay. The risetime of the detector/digitizer is approximately $3 \mathrm{~ns}$ up to $300 \mathrm{MHz}$ ( $2.5 \mathrm{GHz}$ sampling). The laser pulse is probed by a fiber that synchronizes the LFP system with the digitizer operating in the pretrigger mode. All transient spectra were recorded using $10 \times 10 \mathrm{~mm}^{2}$ quartz cells with $4 \mathrm{~mL}$ capacity, and all were bubbled during $20 \mathrm{~min}$ with $\mathrm{N}_{2}$. Absorbance of the samples was kept between 0.2 and 0.3 at the laser wavelength. All the experiments were carried out at room temperature.

\subsection{Computational Methods}

Density functional theory (DFT) calculations were carried out using the B3LYP ${ }^{19}$ exchange correlation functional, together with the $6-31 \mathrm{G}(\mathrm{d})$ and $6-311+\mathrm{G}(\mathrm{d}, \mathrm{p})$ basis sets. ${ }^{20}$ Optimizations were carried out using the Berny analytical gradient optimization method. ${ }^{21,22}$ Electronic structures of stationary points were analyzed using the Wiberg indices. ${ }^{23,24}$ Vertical energies of the singlet and triplet excited states were calculated using the time-dependent (TD-DFT) method. ${ }^{25,26}$ Solvent effects of acetonitrile on the excited states were considered by TD-DFT calculation on the gas-phase structures using a self-consistent reaction field $(\mathrm{SCRF})^{27}$ based on the polarizable continuum model (PCM) of the Tomasi's group. $^{28,29}$ All calculations were carried out with the Gaussian 03 suite of programs. ${ }^{30}$

Acknowledgment. Financial support from the MICINN (Grants: CTQ2009-11027/BQU, CTQ201019909 and pre-doctoral fellowship to P.B.) and the Generalitat Valenciana (Prometeo Program) is gratefully acknowledged.

\section{References and notes}


[1] R.K. Prichard, Parasitology 134 (2007) 1087

[2] H. Das, S. Jayaraman, M. Naika, A. S. Bawa, J. Food Sci. Technol. 44 (2007) 237.

[3] M. Lezcano, W. Al-Soufi, M. Novo, E. Rodriguez-Núñez, J. Vázquez Tato, J. Agric. Food Chem. 50 (2002) 108 .

[4] M. E. Steams, M. Wang, K. Fudge, Cancer Res. 53 (1993) 3073

[5] G. W. Lubega, T.G. Geary, R. D. Klein, R. K Prichard, Mol. Biochem. Parasitol. 62 (1993), 281.

[6] L. Srikanth, V. Varun Raj, N. Raghunandan, L.Venkateshwerlu, Pharma Chemica 3 (2011) 172

[7] Watts, M. T.; Raisys, V. A.; Bauer, L. A. J. Chromatog. 230 (1982) 79

[ 8] G. E. Hardee, M. A. Tshabalala, J. N. Moore, R. D. Gokhales, Res.Vet. Sci. 43 (1987) 13.

[9] M.R. Mahran, M.M. Sidky, H Wamhoff, Chemosphere 12 (1983) 1611.

[10] P.C Tway, L.J. Cline Love, J. Phys. Chem. 86 (1982) 5223.

[11] M C. Jiménez, , M. A. Miranda, I. Vayá, J. Am Chem. Soc. 127 (2005) 10134.

[12] V. Lhiaubet-Vallet, Z. Sarabia, F. Bosca, M. A. Miranda, J. Am. Chem. Soc.126 (2004) 9538

[13] V. Lhiaubet-Vallet, F. Bosca, M. A. Miranda, J. Phys. Chem. B. 111 (2007) 423

[14] I. Vayá, C. J. Bueno, M. C. Jiménez, M. A. Miranda, Chem. Eur. J. 14 (2008) 11284.

[15] S.L. Murov, I. Carmichael, G.L. Hug, Handbook of Photochemistry, Marcel Dekker, Inc.; New York, $2^{\text {nd }}$ edn., 1993.

[16] D. Jornet, R.Tormos, M. A. Miranda, J. Phys. Chem. B. 115 (2011) 10768.

[17] K. Sandros, Acta Chem. Scand. (1964) 2355.

[18] H.A Benesi, J.H. Hildebrand, J. Am. Chem. Soc. 71 (1949) 2703.

[19] C. Lee, W. Yang, R. G. Parr, Phys. Rev. B 37 (1998) 785

[20] W. J. Hehnre, L. Radom, P. v. R. Schleyer, J. A. Pople, Ab initio Molecular Orbital Theory; Wiley: New York, 1986.

[21] H. B. Schlegel, J. Comput. Chem. 3 (1982) 214 
[22] Schlegel, H. B. Geometry Optimization on Potential Energy Surface. In Modern Electronic Structure Theory; Yarkony, D. R., Ed.; World Scientific Publishing: Singapore, 1994.

[23] K. B. Wiberg, Tetrahedron 24 (1968) 1083.

[24] A. E. Reed, R. B.Weinstock, F. J. Weinhold, Chem. Phys. 83 (1985) 735.

[25] R. Bauernschmitt,; Ahlrichs, R. Chem. Phys. Lett. 256 (1996) 454

[26] M. E. Casida, C. Jamorski, K. C. Casida, D. R. Salahud, J. Chem. Phys. 108 (1998) 4439.

[27] J. Tomasi, M. Persico, Chem. Rev. 94 (1994) 2027

[28] E. Cances, B. Mennucci, J. Tomasi, J. Chem. Phys. 107 (1997) 3032

[29] Barone, V., Cossi, M., Tomasi, J. J. Comput. Chem. 19 (1998) 404.

[30] M. J. Frisch, G. W. Trucks, H. B. Schlegel, G. E. Scuseria, M. A. Robb, J.R. Cheeseman, J. A. Jr. Montgomery, T. Vreven, K. N. Kudin, J. C. Burant, J. M. Millam, S. S. Iyengar, J. Tomasi, V. Barone, B. Mennucci, M. Cossi, G. Scalmani, N. Rega, G. A. Petersson, H. Nakatsuji, M. Hada, M. Ehara, K. Toyota, R. Fukuda, J. Hasegawa, M. Ishida, T. Nakajima, Y. Honda, O. Kitao, H. Nakai, M. Klene, X. Li, J. E. Knox, H. P. Hratchian, J. B. Cross, C. Adamo, J. Jaramillo, R. Gomperts, R. E. Stratmann, O. Yazyev, A. J. Austin, R. Cammi, C. Pomelli, J. W. Ochterski, P. Y. Ayala, K. Morokuma, G. A. Voth, P. Salvador, J. J. Dannenberg, V. G. Zakrzewski, S. Dapprich, A. D. Daniels, M. C. Strain, O. Farkas, D. K. Malick, A. D. Rabuck, K. Raghavachari, J. B. Foresman, J. V. Ortiz, Q. Cui, A. G. Baboul, S. Clifford, J. Cioslowski, B. B. Stefanov, G. Liu, A. Liashenko, P. Piskorz, I. Komaromi, R. L. Martin, D. J. Fox, T. Keith, M. A. Al-Laham, C. Y. Peng, A. Nanayakkara, M. Challacombe, P. M. W. Gill, B. Johnson, W. Chen, M. W. Wong, C. Gonzalez, J. A. Pople, Gaussian 03, revision C.02; Gaussian, Inc.: Wallingford, CT, 2004. 